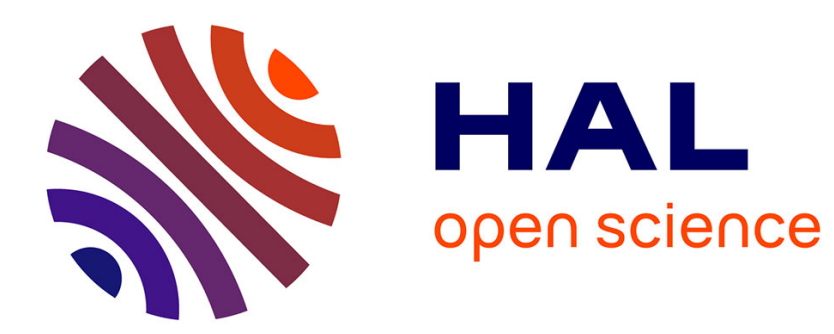

\title{
Open Circuit Voltage of a Lithium ion Battery Model adjusted by data fitting
}

Hanane Hemi, N. M'Sirdi, Aziz Naamane

\section{To cite this version:}

Hanane Hemi, N. M'Sirdi, Aziz Naamane. Open Circuit Voltage of a Lithium ion Battery Model adjusted by data fitting. IRSEC 2018, Dec 2018, Rabat, Morocco. hal-01956283

\section{HAL Id: hal-01956283 \\ https://hal-amu.archives-ouvertes.fr/hal-01956283}

Submitted on 15 Dec 2018

HAL is a multi-disciplinary open access archive for the deposit and dissemination of scientific research documents, whether they are published or not. The documents may come from teaching and research institutions in France or abroad, or from public or private research centers.
L'archive ouverte pluridisciplinaire HAL, est destinée au dépôt et à la diffusion de documents scientifiques de niveau recherche, publiés ou non, émanant des établissements d'enseignement et de recherche français ou étrangers, des laboratoires publics ou privés. 


\title{
Open Circuit Voltage of a Lithium ion Battery Model adjusted by data fitting
}

\author{
Hanane Hemi ${ }^{1,2,3}$, Nacer K M'Sirdi ${ }^{2}$ and Aziz Naamane ${ }^{2}$
}

\begin{abstract}
This paper study the Lithium-ion battery dynamic behaviour and proposes a function to describe the relationship between its Open Circuit Voltage $(O C V)$ and the State of charge $(S O C)$. The effects of environment parameters on the battery behaviour are analyzed. The proposed $O C V$ equation (model) is implemented using MATLAB/Simulink and SimPowerSystems software packages and it is compared with experimental measurements provided by the CALCE group [1].
\end{abstract}

\section{CONTENTS}

\section{INTRODUCTION}

I-A The Context .......... 1

I-B Literature models . . . . . . . . 1

I-C Contribution . . . . . . . . . . 2

II Experimental Data and Test Analysis

III Lithium Ion battery Proposed Model

III-A Lithium Ion battery standard model .

III-B Lithium Ion battery proposed Model .

\section{CONCLUSIONS}

References

\section{INTRODUCTION}

Lithium ion (Li-ion) batteries are nowadays, the favorite energy storage system due to several advantages compared to other technologies. Li-ion battery is an electro-chemical cell that transforms chemical energy into electrical energy. In fact, Li-ion batteries have a high power/energy density, with high cell voltage. They have a high life span, and a low self discharge rate [2], [3]. This type of battery is more and more used in hybrid and electrical vehicle (HEV) systems due to several advantages. It has been compared favourably to other batteries.

\footnotetext{
*This work is supported by SASV group of the LIS UMR CNRS 7020

${ }^{1} \mathrm{Dr}$ Hanane Hemi is Post doc in SASV group of LIS of AMU Hanane. Hemi@uqtr.ca

${ }^{2} \mathrm{~N}$ K M'Sirdi is Laboratory of Informatics and Systems (LIS), CNRS UMR 6168, Saint-Jerome Campus, 13397 Marseille Cedex 20, France. nacer.msirdielis-lab.fr

${ }^{2}$ Aziz Naamane is Laboratory of Informatics and Systems (LIS), CNRS UMR 6168, Saint-Jerome Campus, 13397 Marseille Cedex 20, France. aziz.naamanedis-lab.fr

${ }^{3}$ Research Institute for Solar Energy and New Energies - IRESEN, Morocco.
}

\section{A. The Context}

In Hybrid and Electrical Vehicles (HEV), a Li-ion battery is considered as a secondary source of power used to optimize energy consumption. During a driving cycle, Liion battery can assist a primary source during acceleration and can be charged either per it or by recovering braking energy during deceleration. Then, it plays a significant role in the overall system efficiency. It allows also to reduce the consumption of the primary power source (as for example, the consumption of a hydrogen for a fuel cell vehicle).

However, ambient and storage system temperatures have an negative effect on battery behavior (on current, voltages and State of Charge) and also on its life span.

Studying influence of environmental conditions on the battery performance is essential to minimize its possible degradation and avoid thermal runaway. Then, a good knowledge of the system's heating and heat transfer by the battery, becomes of a crucial importance.

Modeling the behaviour of a Li-ion battery becomes then paramount to study a battery performance, depending on several external or internal conditions. In another hand, a behaviour model is useful to estimate and predict the current and future battery state variables. Its use is also interesting to manage the control for a safe battery operation modes. In another hand we will be able to manage the batteries use such to keep them always in ideal conditions to avoid their aging an faults.

In fact, the ambient temperature has a significant impact on the battery State Of Charge $(S O C)$. Then estimation and / or prediction of the battery SOC will be harder and then it will be harder too to know the optimal charge/discharge current range to control the use of the batteries. However, knowing that $O C V$ and $S O C$ are dependent on ambient temperature, it is important to model this dependence by studying data.

\section{B. Literature models}

The Electrical Equivalent Circuit Models (ECM) are intuitive and easy to handle and are composed by electrical components such as voltage sources, resistors, and capacitors [4], [5]. These models have been used most in electrical engineering simulation, and especially for HEV applications. Indeed, due to their electrical nature which makes them possible to be connected directly to the electrical network [6], [7].

The electrical Equivalent Circuit Models (ECM) can be classified to three categories [8]. The first one is the Thevenin based Electrical Model (TEM) [9]. This model is basic and uses series resistor $R$, an $R C$ parallel network and in 
addition, a voltage source $O C V$ [10]. The second one is the Impedance based Electrical Model (IEM). This model kind is an $\mathrm{AC}$ equivalent impedance model, describing the behaviour in the frequency domain. It has been obtained by an electrochemical impedance spectroscopy [9], [11]. The last one is the Runtime Based Electrical Model (REM). This model simulates battery runtime and DC voltage response for a constant discharge current [9].

\section{Contribution}

In this part of our work, we focus our study on the influence of ambient temperature on battery performance as a representation model parameters. In particular, we analyze the impact of the temperature on the battery Open Circuit Voltage $(O C V)$.

This paper is structured in three sections and a conclusion. The Section II describes the experimental data and Test Analysis. Section III presents the Lithium Ion battery Proposed Model. Section IV presents the conclusions on our results.

\section{EXPERIMENTAL DATA AND TEST ANALYSis}

We consider, in our study, the experimental data provided by the CALCE battery group of a A123 battery cell [1].

In this paper, we selected to study the A123 battery cell which is a LiFePO4 battery. Tab.I shows the battery characteristics given by battery manufacturer [12].

TABLE I: Battery characteristics given by battery manufacturer [12]

\begin{tabular}{lcc}
\hline Type & \multicolumn{2}{c}{$\mathrm{LiFePO} 4$} \\
Nominal capacity & 1.1 & $\mathrm{Ah}$ \\
Nominal voltage & 3.3 & $\mathrm{~V}$ \\
Upper cut-off voltage & 3.6 & $\mathrm{~V}$ \\
Lower cut-off voltage & 2 & $\mathrm{~V}$ \\
Maximum continuous discharge current & 30 & $\mathrm{~A}$ \\
\hline
\end{tabular}

The database is proposed by the CALCE battery group [1], [13]. They have used these data to define a battery description using look u tables.

The main motivation of this choice is that this type of battery is typically used in HEV applications.

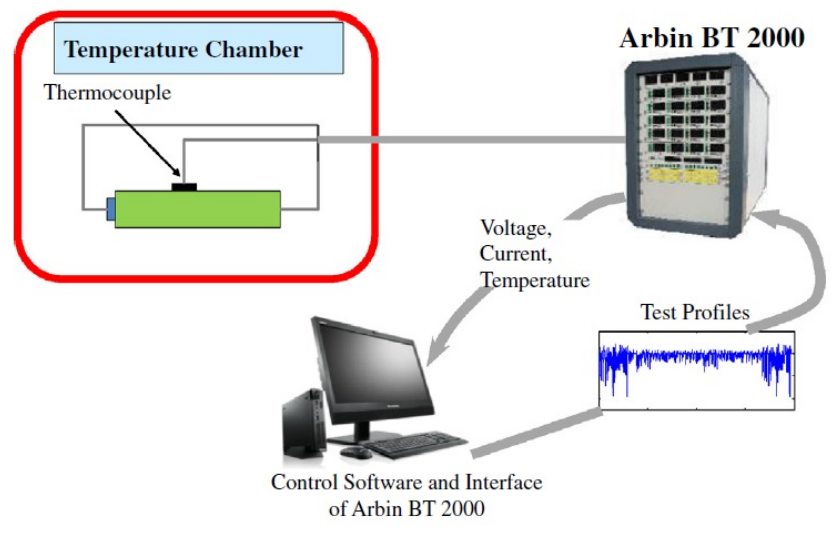

Fig. 1: Test bench for battery tests experiments [14]
The objective of our work in this step is to study the relationship between the $O C V, S O C$ and the ambient temperature. In order to ensure this, a low-current $O C V$ method is used for this test.

The Low-current $O C V$ test consists in using a small current to charge and discharge the battery and then measure the output voltage which is approximately equal to $O C V$. This test have been performed, by the CALCE battery group, for an ambient temperature varying from $-10{ }^{\circ} \mathrm{C}$ to $50{ }^{\circ} \mathrm{C}$ with interval of $10{ }^{\circ} \mathrm{C}$.

Fig. 1 presents the test bench for battery tests experiments [14]. Test bench detail has been given by the CALCE battery group in the References [1], [14].

Fig. 2 presents $O C V$ vs time in discharge mode under a Low constant current. As shown, battery takes a long time to discharge because of the nature of this test (Lowcurrent $O C V$ test). We can also, compare the $O C V$ curves at different ambient temperatures. Notice that the time taken to discharge the battery and the $O C V$ values depend on temperature.

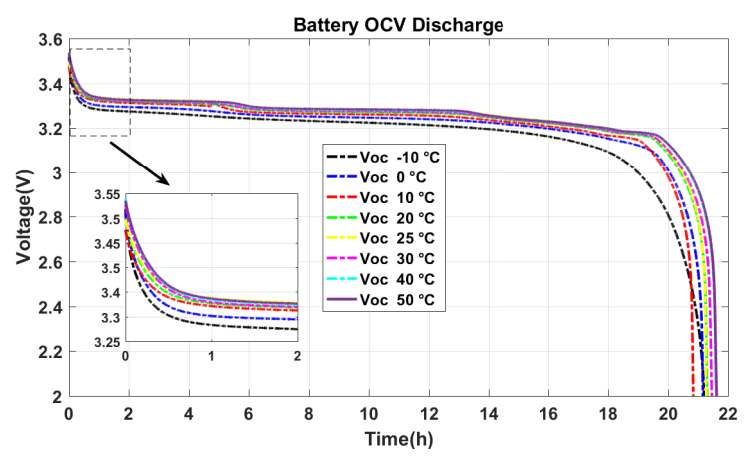

Fig. 2: $O C V$ vs time at discharge mode

Fig.3 presents the $O C V$ vs the Capacity in the discharge mode. As shown in the previous figure, the ambient temperature has an impact on battery behavior. In fact, the relation between $O C V$ and battery capacity in discharge mode, is affected by the temperature.

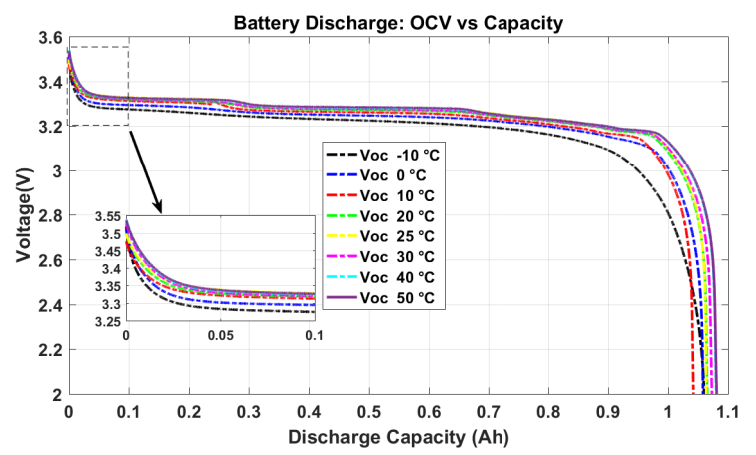

Fig. 3: $O C V$ vs Capacity at discharge mode

We can remark that, in Fig. 2 and 3, there are three main regions: two region with a quasi exponential decrease (from 0 to $0.1 \mathrm{Ah}$ and from 0.9 to $1.1 \mathrm{Ah}$ ) and a middle region 
which has a quasi linear decrease. The same temperature effects are observed when the battery is in the charge mode.

\section{Lithium ION BATTERy PROPOSED MOdel}

Li-ion battery is considered as a part of the HEV system model. Therefore, to predict a HEV behavior in real time. The choice of the battery model is important for a real time HEV operation, and especially, the battery $S O C$ model must be relevant to estimate and predict the BMS (Battery Management System) calculation. For these reasons, a good model is a key factor for control in real time operating. Thus, fast battery models are preferred compared with complex models. In fact, a battery used in HEV applications is a pack composed by several battery cells organized in series and parallel depending on the battery pack design. The electrical equivalent circuit model has a simple design and also has a fast computation time in both cells or pack battery models. However, the electrochemical model describes a single cell and is not suitable for real time applications, specially for HEV applications, due its complex equations which are hard to implement and then required a long time of computation.

\section{A. Lithium Ion battery standard model}

Fig.4 shows the ideal battery curve during a constant current discharge [15]. The Shepherd model describes by a mathematical equation, the relationship between the voltage $\left(V_{\text {Batt }}(t)\right)$, current $(i(t))$ for a constant current discharge. Eq.1 represents this relationship [15], [16]. In fact, the battery cell voltage is composed of an internal resistance $R$ and the open-circuit voltage $(O C V)$ given in Eq.2.

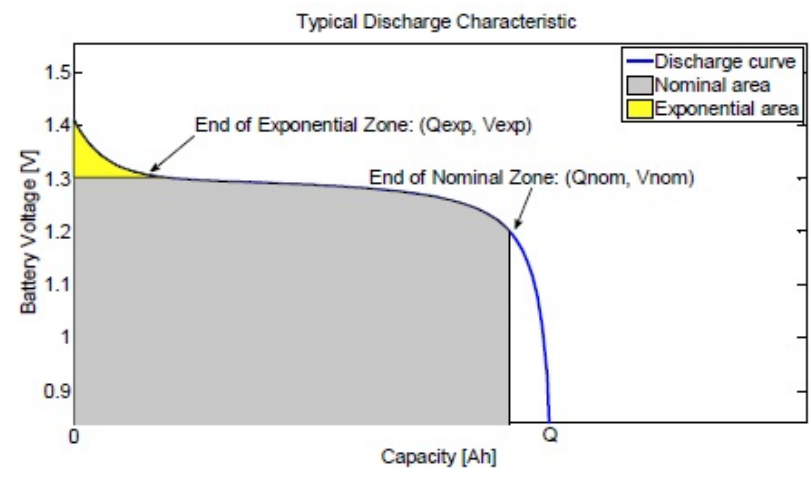

Fig. 4: Ideal battery curve during discharge [17]

$$
\begin{gathered}
V_{\text {Batt }}(t)=V_{0}-\frac{K . Q}{Q-i . t} . i(t)-R . i(t) \\
V_{o c}(t)=V_{0}-\frac{K . Q}{Q-i . t} . i(t)
\end{gathered}
$$

where $V_{0}$ is the constant voltage $(V), Q$ is the maximum capacity $(A h), i . t$ is the discharged capacity $(A h), K$ is the polarization constant $(A h)^{-1}$ and $R$ is internal resistance. To improve a battery mathematical model to fit to battery charge and discharge curves, the Shepherd model is modified by adding some terms. Eq.3 and Eq.4 show expression of the $O C V$ at discharge and charge modes respectively [15], [17], [16]. If the current is positive, then the battery is in discharge mode, $O C V=V_{\text {oc.Discharge }}$, as shown in Eq.3. If the current is negative, then the battery is in the charge mode, $O C V=V_{\text {oc.Charge }}$, as presented in Eq.4.

$$
\begin{aligned}
& V_{\text {oc.Discharge }}=V_{0}-\frac{K . Q}{Q-i . t} \cdot i^{*}-\frac{K . Q}{Q-i . t} \cdot i . t+A * \exp (-B . i . t) \\
& V_{\text {oc.Charge }}=V_{0}-\frac{K . Q}{0.1 * Q-i . t} \cdot i^{*}-\frac{K . Q}{Q-i . t} \cdot i . t+A . \exp (-B . i . t)
\end{aligned}
$$

where $A$ is the exponential voltage coefficient (in $V$ ), $B$ is the exponential capacity (in $(A h)^{-1}$ and $i^{*}$ is the filtered current (in $A$ ).

This model is quite adequate but it can be enhanced to be more precise and take into account the non linearity.

\section{B. Lithium Ion battery proposed Model}

In Li-ion battery, the relationship between OCV and SOC is a non linear function. Therefore, the battery chosen must have a NonLinear Equivalent RC Circuits to Model (NL$\mathrm{ECM}$ ) to describe this non linear relationship function. The NL-ECM model proposed here for the battery is composed by an OCV, a capacitance to model polarization effect $\left(C_{p}\right)$, a propagation resistor to model propagation resistance $\left(R_{p}\right)$, a diffusion resistor as a function of current $\left(R_{d}\right)$, an ohmic resistance $\left(R_{o}\right)$, and battery voltage $\left(V_{\text {Batt }}\right)$. The Fig.5 presents the proposed battery Li-ion NL Equivalent Circuit Model (NL-ECM).

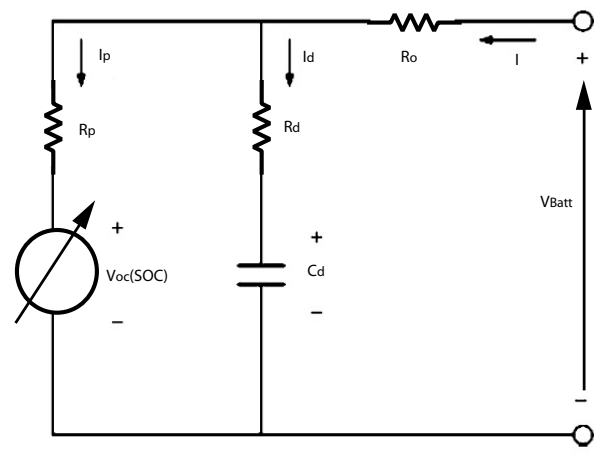

Fig. 5: Proposed NL-ECM battery Li-ion model

Based on the measurement presented in section II, we have shown the impact of temperature on battery behavior. In fact, the $V_{o c}$ measured during discharge mode, is different for each temperature. This difference is emphasized in $O C V$ and the capacity maximum and the exponential and the nominal zones (in the Fig.2 and Fig.3). These curves fitting has been deployed to fit data to a function. In this paper, we have chosen a rational polynomials function to find a relationship between $O C V$ and $S O C$. This function has a numerator polynomial with a second degree and a denominator polynomial of a third degree. The degrees of the numerator and the denominator polynomial have been chosen to get the best curve fitting and minimum number of coefficients. 
The Eq.5 represents the $O C V$ function which produces the best fit. In addition, this function has been tested for several ambient temperatures.

$$
V_{o c}(S O C)=\frac{p 1 * S O C^{2}+p 2 * S O C+p 3}{S O C^{3}+q 1 * S O C^{2}+q 2 * S O C+q 3}
$$

where $p_{i}$ are the coefficients of the numerator polynomial, $q_{j}$ are the coefficients of the denominator polynomial, and $S O C$ is given by Eq.6.

$$
S O C=\frac{i . t}{Q}
$$

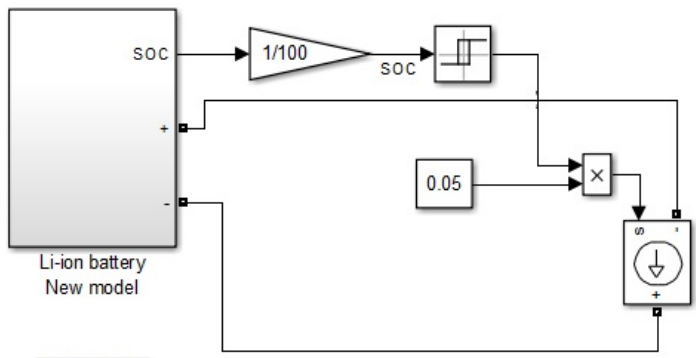

$$
\begin{array}{r}
\text { Discrete, } \\
\text { fis }=0.01
\end{array}
$$$$
\text { pow ergui }
$$

(a)

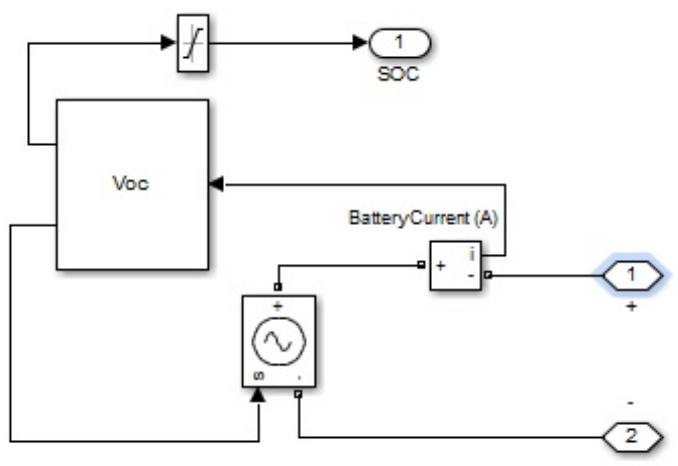

(b)

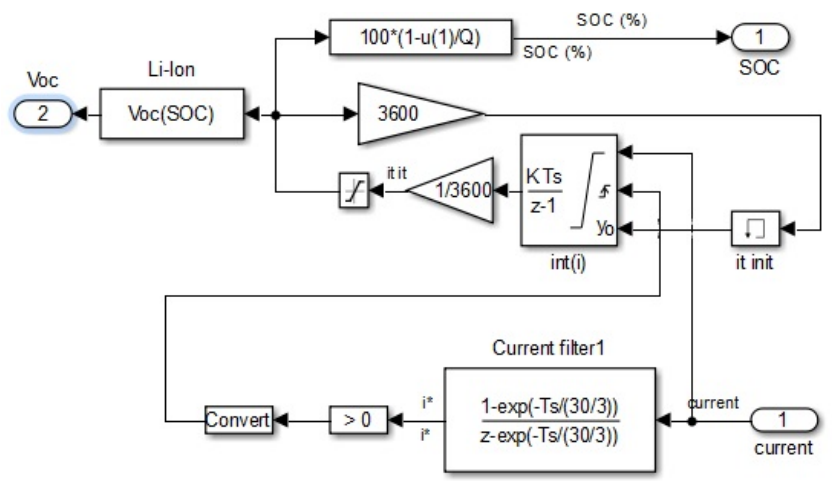

(c)

Fig. 6: Battery model

The battery model shown in Fig.6 is used in simulation using MATLAB/Simulink and SimPower Systems software packages, for validation tests. As mentioned in section II, the test used in this simulation is the Low-current $O C V$ test. In fact, it consist by using a small current to charge and discharge the battery.

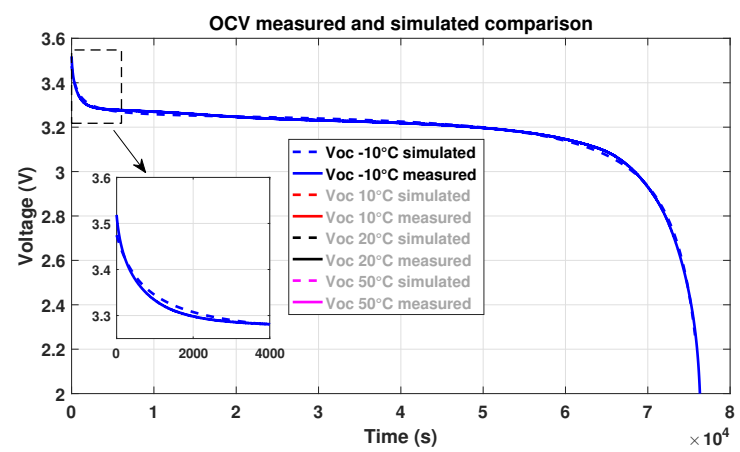

(a)

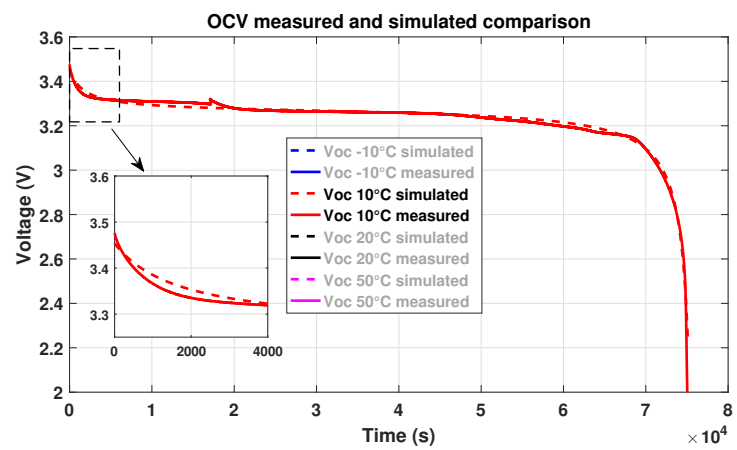

(b)

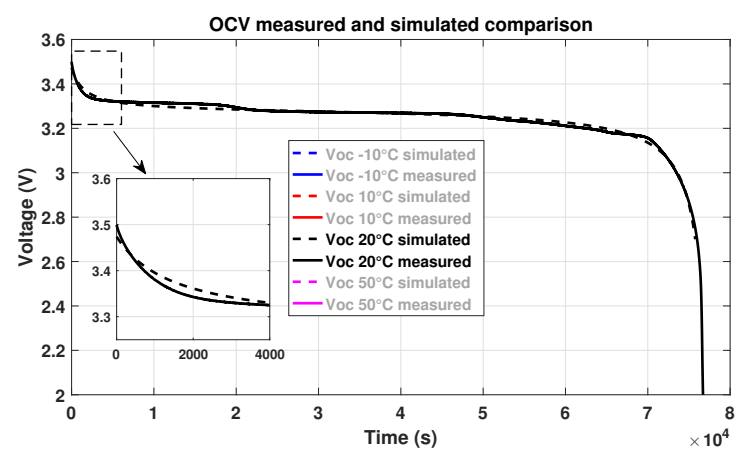

(c)

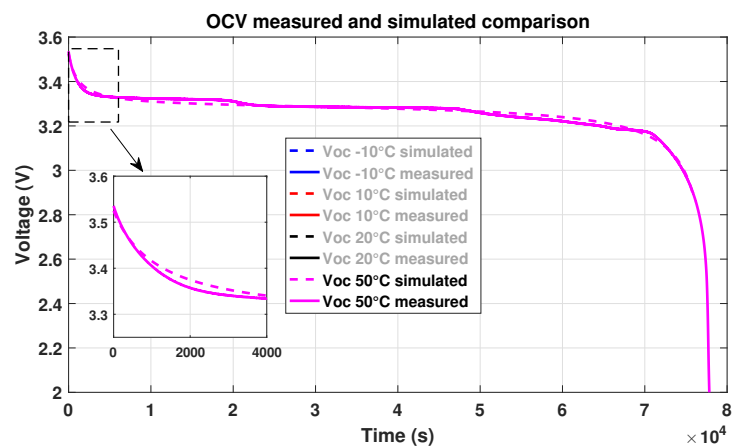

(d)

Fig. 7: $V_{o c}$ measured and simulated comparison 
In this case, the current used to discharge a battery is equal to $0.05 A$ as shown in Fig.6a. Therefore, the output voltage measured is approximately equal to $V_{B a t t}=V_{o c}$ as presented in Fig.6b. The $O C V$ equation (Eq.5) is implemented as shown in the Fig.6c.

Fig.7 shows the $O C V$ measured and simulated comparison for ambient temperature $-10{ }^{\circ} \mathrm{C} \quad 10{ }^{\circ} \mathrm{C} \quad 20{ }^{\circ} \mathrm{C}$ and $50{ }^{\circ} \mathrm{C}$. The simulation results shows a small error between simulations and measurements for each temperature.

We remark in all the validations tests that the simulated curves using our model are in excellent concordance with the real data ones. The modeling errors are very small.

\section{CONCLUSIONS}

The paper presented a data curve fitting used to find a relationship between $O C V$ and $S O C$ for different temperatures. This equation had been implemented and simulated using MATLAB/Simulink and SimPower Systems software packages. The comparison between simulation and measurement shows a small error due to a complex dynamic of battery. In The next step of this study, the function of $O C V$ will be improved to minimize the error and then the battery model behavior at different temperatures will be developed and completed.

\section{ACKNOWLEDGMENT}

The authors would like to thank Professor Michael Pecht, from the CALCE battery group, for sharing their experimental data and exchanges, to let us being able to use them for the validation of our model. The "CALCE" is the Center for Advanced Life Cycle Engineering. See https://web.calce.umd.edu/batteries/index.h

\section{REFERENCES}

[1] "CALCE: center for advanced life cycle engineering," https://web.calce.umd.edu/batteries/index.html.

[2] Y. Tian, D. Li, J. Tian, and B. Xia, "State of charge estimation of lithium-ion batteries using an optimal adaptive gain nonlinear observer," Electrochimica Acta, vol. 225, pp. 225-234, 2017.

[3] T. Waldmann, B.-I. Hogg, and M. Wohlfahrt-Mehrens, "Li plating as unwanted side reaction in commercial li-ion cells-a review," Journal of Power Sources, vol. 384, pp. 107-124, 2018.

[4] K. Li, F. Wei, K. J. Tseng, and B.-H. Soong, "A practical lithiumion battery model for state of energy and voltage responses prediction incorporating temperature and ageing effects," IEEE Transactions on Industrial Electronics, vol. 65, no. 8, pp. 6696-6708, 2018.

[5] N. M'sirdi, A. Belhani, and A. Naamane, Battery models for estimation of state of charge by sliding mode observer, 2012, vol. 12.

[6] A. Shafiei, A. Momeni, and S. S. Williamson, "Battery modeling approaches and management techniques for plug-in hybrid electric vehicles," in Vehicle Power and Propulsion Conference (VPPC), 2011 IEEE. IEEE, 2011, pp. 1-5.

[7] X. Hu, S. Li, and H. Peng, "A comparative study of equivalent circuit models for li-ion batteries," Journal of Power Sources, vol. 198, pp. 359-367, 2012.

[8] K. Benabdelaziz and M. Maaroufi, "Battery dynamic energy model for use in electric vehicle simulation," International Journal of Hydrogen Energy, vol. 42, no. 30, pp. 19496-19503, 2017.

[9] M. Chen, G. A. Rincon-Mora et al., "Accurate electrical battery model capable of predicting runtime and iv performance," IEEE transactions on energy conversion, vol. 21, no. 2, pp. 504-511, 2006.

[10] H. He, X. Zhang, R. Xiong, Y. Xu, and H. Guo, "Online model-based estimation of state-of-charge and open-circuit voltage of lithium-ion batteries in electric vehicles," Energy, vol. 39, no. 1, pp. 310-318, 2012.
[11] H. Dai, B. Jiang, and X. Wei, "Impedance characterization and modeling of lithium-ion batteries considering the internal temperature gradient," Energies, vol. 11, no. 1, p. 220, 2018.

[12] "A123systems high power lithium ion apr18650m1a datasheet," https://www.batteryspace.com/prod-specs/6612.pdf.

[13] Y. Xing, W. He, M. Pecht, and K. L. Tsui, "State of charge estimation of lithium-ion batteries using the open-circuit voltage at various ambient temperatures," Applied Energy, vol. 113, pp. 106-115, 2014.

[14] W. He, N. Williard, C. Chen, and M. Pecht, "State of charge estimation for li-ion batteries using neural network modeling and unscented kalman filter-based error cancellation," International Journal of Electrical Power \& Energy Systems, vol. 62, pp. 783-791, 2014.

[15] E. Raszmann, K. Baker, Y. Shi, and D. Christensen, "Modeling stationary lithium-ion batteries for optimization and predictive control," in Proceedings of the 2017 IEEE Power and Energy Conference at Illinois (PECI), Champaign, IL, USA, 2017, pp. 23-24.

[16] S. Li and B. Ke, "Study of battery modeling using mathematical and circuit oriented approaches," in Power and Energy Society General Meeting, 2011 IEEE. IEEE, 2011, pp. 1-8.

[17] D. Gallo, C. Landi, M. Luiso, and R. Morello, "Optimization of experimental model parameter identification for energy storage systems," Energies, vol. 6, no. 9, pp. 4572-4590, 2013. 